\title{
METHOD DEVELOPMENT AND VALIDATION OF NORETHINDRONE ACETATE ASSAY AND ITS RELATED IMPURITIES IN API AND PHARMACEUTICAL FORMULATION WITH ORTOGONAL DE- TECTOR TECHNQUES
}

\author{
J. SATISH1,2*, P. RADHAKRISHNANAND1,2, K. SURENDRA BABU² \\ ${ }^{1}$ Faculty of Science, Pacific Academy of Higher Education and Research University, Udaipur, Rajasthan, India, ${ }^{2}$ United States Pharma- \\ copeia-India Private Limited, Research and Development, Laboratory, ICICI Knowledge Park, Turkapally, Shameerpet, Hyderabad, India \\ Email: janumpallyabhi@gmail.com \\ Received: 10 May 2017 Revised and Accepted: 02 Nov 2017
}

\section{ABSTRACT}

Objective: To develop and validate a sensitive and stability indicating gradient reverse phase ultra-high performance(UHPLC-PDA) liquid chromatography with photodiode array(PDA) and mass spectroscopy (MS) of Norethindrone Acetate (NA) assay and organic impurities (OI) in active pharmaceutical Ingredient(API) and Pharmaceutical Formulation (PF).

Methods: The chromatographic conditions were optimized using Zorbax SB-C18 analytical UHPLC column with the dimensions (100 x 2.1) mm and $1.8 \mu \mathrm{m}$ particle sizes. The mobile phase consisted of water (solution A) and acetonitrile (solution B) with gradient elution as mentioned time (min)/\% Solution B: Initial/40,0.2/40, 9.2/55,12.0/55,12.2/90,15.5/90, 15.8/40 and 18.0/40. The flow rate was at the rate of 0.4 ml/min and the detection wavelengths were $254 \mathrm{~nm}$ and $210 \mathrm{~nm}$. The column was kept at $40{ }^{\circ} \mathrm{C}$ and the injection volume was $5 \mu \mathrm{L}$. Stability of NA sample in different conditions was investigated by exposing the drug to stress study utilizing acid, base, oxidation, thermal, Humidity and photolytic.

Results: There was no interference from excipients, impurities or degradation products at the retention time of NA about 9.1 min indicating the specificity of the method.

The drug showed good stability under oxidation, thermal, humidity and photolytic conditions, but significant degradation was observed under acid and base conditions. The procedure was validated for specificity, linearity, accuracy, precision and robustness. The degradation products were well resolved from NA and its impurities. The obtained LOD (Limit of detection) values are 0.001\% to 0.015\% and LOQ (Limit of quantification) values are $0.003 \%$ to $0.05 \%$ of impurities.

Conclusion: A sensitive, rapid, specific and stability indicating gradient Reverse Phase UHPLC-PDA-PDA with MS (Orthogonal detectors) method for the determination of NA for the assay and organic impurities was successfully developed. The developed method was validated to be specific, linear, accurate, precise and robust. The peak purity and LC-MS test results confirmed that the NA peak was homogenous in all stress samples and the mass balance was found to be more than $99 \%$, thus proving the stability indicating power of the method

Keywords: UHPLC-PDA and MS, Orthogonal Detectors, Norethindrone acetate, Stress studies and validation

(C) 2017 The Authors. Published by Innovare Academic Sciences Pvt Ltd. This is an open access article under the CC BY license (http://creativecommons.org/licenses/by/4.0/) DOI: http://dx.doi.org/10.22159/ijpps.2017v9i12.19856

\section{INTRODUCTION}

NA is a synthetic progestagenic compound and widely used for hormone replacement therapy and contraception is a female hormone. This medicine is used to treat endometriosis, uterine bleeding caused by abnormal hormone levels, and secondary amenorrhea. Secondary amenorrhea is when a woman stops getting menstrual periods due to low levels of certain female hormones. Chemically NA is (8R,9S,10R,13S,14S,17S)-17ethynyl-13-methyl-3-oxo-,3,6,7,8,9,10,11,12,13,14,15,16,17-tetradecahydro-1H-cyclopenta[a]phenanthren-17-yl acetate. Chemical structures of NA and its organic impurities shown fig. 1. Impurity profiling of active pharmaceutical ingredients (API) and PFs is part of the most challenging tasks of pharmaceutical analytical chemists under industrial environment. Literature reveals that there are only few analytical methods for the estimation of NA in bulk and pharmaceu- tical dosage forms by HPLC [1-4] and Gas chromatography and mass spectrometry [5]. There have a coupled of reports of analysis of longer run time with HPLC assay methods and no organic impurities methods. An extensive literature indicates that till date there is not a single method has been reported for the determination of impurities either in bulk drugs or in PFs of NA with UHPLC-PDA and MS.

To the best of our knowledge, until now there is no stability indicating UHPLC-PDA and MS method except European Pharmacopoeia, $9^{\text {th }}$ Edition 2017(9.2) with longer run time ( $>60 \mathrm{~min}$ ) for the determination of NA and its organic impurities.

The aim of this study is to develop a simple, rapid, specific and stability indicating UHPLC-PDA and MS method for detection and quantification of NA and its organic impurities in API and PF.

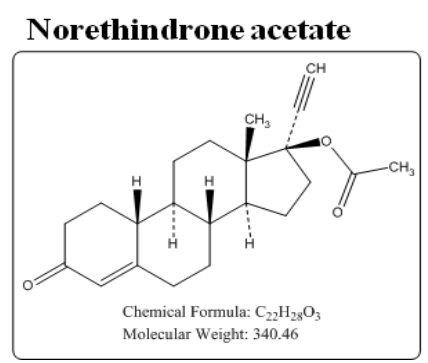

Impurity-1

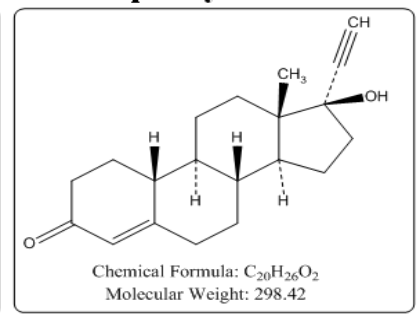

Impurity-2

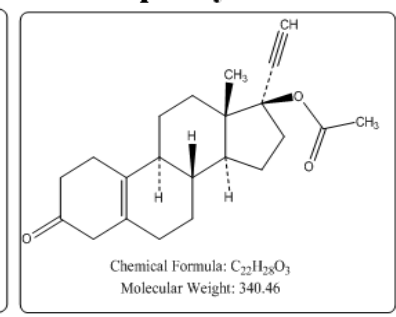


Impurity-3

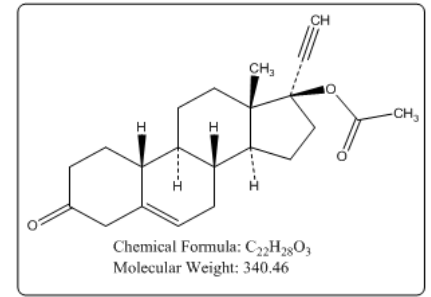

Impurity-6
Impurity-4

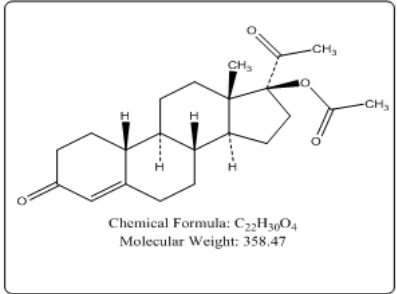

Impurity-7
Impurity-5

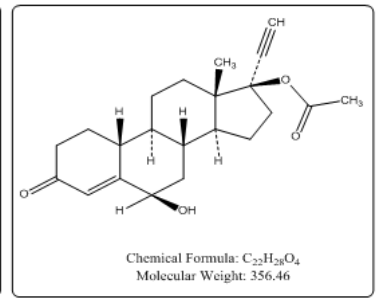

Impurity-8

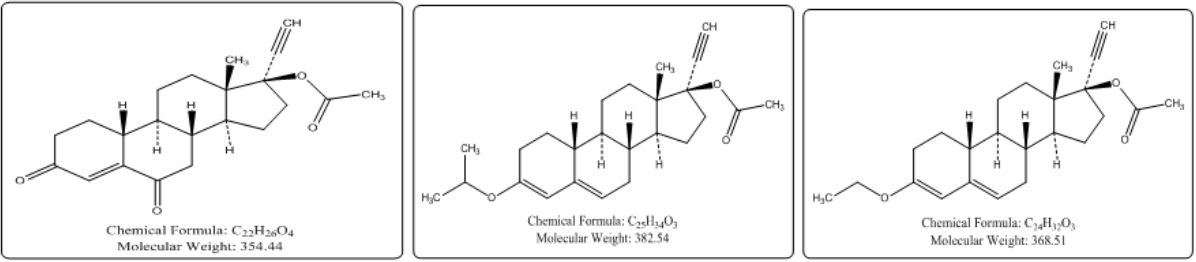

Impurity-9

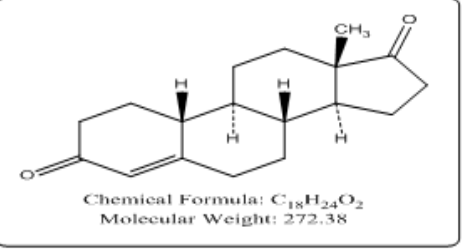

Fig. 1: Chemical structure of NA and its impurities

In this work, the linearity range of the calibration curve was extended to make the method suitable for the assay and organic impurities, because of its speed and sensitivity, this technology has been used in this work to develop a new UHPLC-PDA and MS method with shorter run time (18 $\mathrm{min}$ ) with nine impurities. This method is capable of separate all the impurities from the NA and with a resolution minimum of 2.0. This method was used for further method validation.

UHPLC-PDA and MS are separation and specific identification technique (Orthogonal detector approach) based upon well-established principles of liquid chromatography, which utilizes sub- $2 \mu \mathrm{m}$ particles as the stationary phase. These particles operate at elevated mobile phase linear velocities to affect dramatic increases in resolution, sensitivity, and speed of analysis. Hence, an attempt has been done to develop an accurate, rapid, specific and reproducible method for determination of NA impurities with API and in PF.

\section{MATERIALS AND METHODS}

\section{Chemicals and reagents}

Samples of NA API, tablets and its related impurities were obtained from USP-India, Hyderabad, India and water from sartorius, resistance 18.2 (Mega $\Omega-\mathrm{cm}$ ), acetonitrile, methanol, hydrochloric acid and sodium hydroxide (Merck grade). All other organic solvents used were either of analytical reagent or the high-performance liquid chromatography grade.

\section{Instrumentation}

The UHPLC-PDA system was comprised of a Waters H-Class system with Empower 3 software. Agilent-MS 6460 Triple Quad with LC1290, Balances: Sartorius, Photostability chamber (SUNTEST XLS+), Hot Air Oven (Memmert), Humidity Chamber (ESPEC)

\section{Chromatographic conditions}

The chromatographic separation was performed using a Zorbax SBC18 analytical UHPLC-PDA column with the dimensions $(100 \times 2.1)$ $\mathrm{mm}$ and $1.8 \mu \mathrm{m}$ particle sizes. The flow rate was set at $0.4 \mathrm{ml} / \mathrm{min}$ and the detection wavelengths were $254 \mathrm{~nm}$ and $210 \mathrm{~nm}$. The column was maintained at $40{ }^{\circ} \mathrm{C}$ and the injection volume was $5 \mu \mathrm{L}$ used. The mo- bile phase consisted of water (solution A) and acetonitrile (solution B) with Gradient elution as mentioned time $(\mathrm{min}) / \%$ Solution B: Initial/40,0.2/40, 9.2/55,12.0/55,12.2/90,15.5/90, 15.8/40 and 18.0/40.

\section{MS conditions}

Compounds were detected on an Agilent-LCMS 6460 Triple Quad. Chromatographic type: ESI: Ion Source: ESI-AJS, Gas temp: $300{ }^{\circ} \mathrm{C}$, Gas flow 10 Lit min $^{-1}$, Nebulizer: 45 PSI, Sheath gas Temp: $400{ }^{\circ} \mathrm{C}$, Sheath gas flow: $11 \mathrm{Lit} \mathrm{min}^{-1}$ and capillary voltage: $3500 \mathrm{~V}$.

\section{Sample and solution preparations}

Diluent: Water and Acetonitrile (40:60 v/v)

\section{Preparation of NA assay standard and sample solution}

A stock solution of NA ( $1000 \mu \mathrm{g} / \mathrm{ml})$ was prepared by dissolving an appropriate amount of diluent. Working solution was to be established from above stock solution for assay determination (100 $\mu \mathrm{g} / \mathrm{ml}$ of NA) in diluent.

\section{Preparation of NA tablet assay sample preparation}

Twenty tablets were weighed and average weight of the tablet was calculated and finely powdered Tablets. Tablet powder equivalent to $10 \mathrm{mg}$ of API was transferred in to a $100 \mathrm{ml}$ volumetric flask. To this added $70 \mathrm{ml}$ of diluent and sonicated for $30 \mathrm{~min}$ with intermediate shaking. The solution was subsequently diluted to $100 \mathrm{ml}$ with diluent and centrifuged at $3000 \mathrm{rpm}$ for $10 \mathrm{~min}$. The supernatant clear solution $(100 \mu \mathrm{g} / \mathrm{ml})$ was collected, filtered through $0.22 \mu \mathrm{m}$ filter and used as the sample solution.

\section{Preparation of organic impurities (OI) standard preparation}

A stock solution of NA and its impurities $(20 \mu \mathrm{g} / \mathrm{ml})$ was prepared by dissolving an appropriate amount of diluent. Working solution was prepared from above stock solution to determine the organic impurities $(1 \mu \mathrm{g} / \mathrm{ml})$ in diluent.

\section{Preparation of NA organic impurities sample preparation}

Taken NA of about $10000 \mu \mathrm{g}$ to a $10 \mathrm{ml}$ volumetric flask and dissolved and diluted to volume with diluent $(1000 \mu \mathrm{g} / \mathrm{ml})$. 


\section{Preparation of NA tablet OI sample preparation}

Twenty tablets were weighed and average weight of the tablet was calculated and finely powdered Tablets. Tablet powder equivalent to $100 \mathrm{mg}$ of was transferred in to a $100 \mathrm{ml}$ volumetric flask. To this added $70 \mathrm{ml}$ of diluent and sonicated for $30 \mathrm{~min}$ with intermediate shaking. The solution was subsequently diluted to $100 \mathrm{ml}$ with diluent and centrifuged at $3000 \mathrm{rpm}$ for $10 \mathrm{~min}$. The supernatant $(1000$ $\mu \mathrm{g} / \mathrm{ml}$ ) was collected, filtered through $0.22 \mu$ filter and used as the sample solution.

\section{Methods}

\section{Method validation}

The method was validated for system suitability, specificity, precision, sensitivity, linearity, accuracy and robustness [6-8].

\section{System suitability}

System suitability parameters were carried out to verify the system performance. System precision was established on six replicate injections of OI standard preparation and assay standard preparation. All the essential characteristics, including the relative standard deviation (\%RSD), USP tailing, USP plate count and USP resolution were measured. These all system suitability parameters covered the system, method and column performance.

\section{Specificity}

Stress studies were carried out with an initial concentration of 100 $\mu \mathrm{g} / \mathrm{ml}$ of NA in API and formulated sample to provide the stability indicating property and specificity of the method. Intentional degradation was attempted by the stress conditions of exposed to acid $(0.1 \mathrm{~N} \mathrm{HCl}$ for $24 \mathrm{~h}$ at room temperature), base $(0.1 \mathrm{~N} \mathrm{NaOH}$ for 1 hour at room temperature), oxidation (3\% peroxide for $24 \mathrm{~h}$ at room temperature), Thermal (Exposed at $105{ }^{\circ} \mathrm{C}$ for $48 \mathrm{~h}$ ), humidity (Exposed to $85{ }^{\circ} \mathrm{C}$ and $85 \% \mathrm{RH}$ for $3 \mathrm{~d}$ ) and photolytic stress (1.2 million lux hours followed by 200 watt-hours per square meter).

\section{Precision}

The precision of the organic impurities method was checked by injecting sample preparation and six individual preparations of NA $(1000 \mu \mathrm{g} / \mathrm{ml})$ spiked with $0.1 \%$ each of impurity-1, impurity-2, impurity-3, impurity-4, impurity-5, impurity-6, impurity-7, impurity-8 and impurity-9. The RSD (\%) of impurity-1, impurity-2, impurity-3, impurity-4, impurity-5, impurity-6, impurity-7, impurity-8 and impurity-9 content was calculated. Intermediate precision (ruggedness) was evaluated by a different analyst in the same laboratory. Assay method precision was evaluated by performing six independent assays of a sample solution of NA against a qualified standard and calculation of the RSD (\%). Intermediate precision of the assay method was evaluated by a different analyst in the same laboratory.

\section{Limit of detection (LOD) and limit of quantification (LOQ)}

A signal to noise ratio $3: 1$ is generally considered acceptable for estimating the detection limit. A typical signal to noise ratio is 10:1is generally considered acceptable for estimating the quantification limit.

\section{Linearity}

Impurity linearity solutions were prepared from stock solutions at five concentration levels from 0.05 to $0.15 \%$ of analyte concentration. The peak area versus concentration data was subjected to least-squares linear regression analysis. The calibration curve was obtained by plotting impurity areas against the concentration expressed in $\mu \mathrm{g} / \mathrm{ml}$. Assay linearity solutions were prepared from stock solution at five concentration levels from $80 \%$ to $120 \%$ of analyte concentration. The peak area versus concentration data was subjected to least-squares linear regression analysis. The calibration curve was drawn by plotting NA areas against the concentration expressed in $\mu \mathrm{g} / \mathrm{ml}$.

\section{Accuracy}

The accuracy of an analytical procedure expresses the closeness of agreement between the true value and the observed value. Impurity accuracy of the method was demonstrated at three different concentration levels. The analysis was carried out by spiking all the impurities on the API and formulation samples at $0.05,0.10$ and $0.15 \%$ of the NA concentration $(1000 \mu \mathrm{g} / \mathrm{ml})$. The percentage mean recoveries at each level for all the impurities were calculated. Assay accuracy of the method was demonstrated at three different concentration levels. The analysis was carried out for assay on the API and formulation samples at 80,100 and $120 \%$ of the NA concentration $(100 \mu \mathrm{g} / \mathrm{ml})$. The percentage mean recoveries at each level for NA calculated.

\section{Robustness}

To determine the robustness of the developed method, experimental conditions were deliberately changed and the resolution between NA and its impurities; tailing factor and theoretical plates of NA peak were evaluated. To study the effect of the flow rate on the developed method, it was changed from $0.36 \mathrm{ml} / \mathrm{min}$ and $0.44 \mathrm{ml} / \mathrm{min}$ (Instead of $0.4 \mathrm{ml} / \mathrm{min}$ ), The effect of column temperature on the developed method was studied at $35^{\circ} \mathrm{C}$ and $45^{\circ} \mathrm{C}$ (Instead of $40^{\circ} \mathrm{C}$ ) and Initial gradient changed with $+10 \%$ and $-10 \%$ of organic $(\% \mathrm{~B})$. In all the above varied conditions, the component of the mobile phase was kept constant.

\section{Stability in solution and in the mobile phase}

NA spiked samples (Impurities spiked at $0.1 \%$ of analyte concentration) and NA assay samples were prepared in the diluent and leaving the test solutions at room temperature. The spiked sample and assay samples were injected at $0,24,48 \mathrm{~h}$ time intervals. The peak area was estimated and the consistency in the \% variation each impurity at each interval was checked. The prepared mobile phase was kept constant during the study period. The mobile phase study was demonstrated by injecting the freshly prepared sample solution at distinct time intervals $(0-2 \mathrm{~d})$.

\section{RESULTS AND DISCUSSION}

\section{Optimization of chromatographic conditions}

The main criterion for developing an RP-UHPLC-PDA and MS method for the determination of impurities in NA API and tablets in a single run, with emphasis on the method being a stability indicating, specific, linear, accurate, precise, robust and free of interference from other formulation excipients and convenient enough for routine use in quality control laboratories.

Individual stock solutions of NA and its impurities were scanned in PDA in the range of 200 to $400 \mathrm{~nm}$ and checked the spectra of each component. From the spectra, some of the impurities were having an absorbance maximum at about $238 \mathrm{~nm}$ to $256 \mathrm{~nm}$. Hence $254 \mathrm{~nm}$ was selected for the estimation of NA all impurities except impurity2 and impurity-3. Low absorbance observed for impurity-2 and impurity-3. Hence $210 \mathrm{~nm}$ was selected for the estimation of Impurity- 2 and impurity-3. The typical spectra's for NA and its impurities were presented in the fig. 2 and fig. 3 . In case of impurity profiling study, the primary goal of the method development is to separate the drug from impurities (resolution $[\mathrm{Rs}]>2$ ) that impact on the quality assessment of the PF. In addition, sensitivity of the method is also very crucial for detection of low-level impurities during routine drug analysis. Other factors, such as the need for short analysis time (18 $\mathrm{min}$ ) are also considered by incorporating agilent stable band column in the study. In the present RP-UHPLC-PDA and MS method, stationary phase, organic modifiers and its composition, gradient time $(\mathrm{tG})$, flow rate, and column temperature are critically influencing risk-assessment parameters for ionizable analytes. All critical parameters should be examined at a time to ensure the effect of one factor in the presence of others. Nevertheless, the factorial combination of all parameters leads to various numbers of experiments. Hence, the method development was made into two subparts, first screening started with the key parameters that are mainly responsible for the selectivity followed by optimization study in the presence of secondary influencing parameters (e. g. flow rate, column temperature and gradient) NA sample preparation $(1000 \mu \mathrm{g} / \mathrm{ml})$ spiked with all the impurities $(1 \mu \mathrm{g} / \mathrm{ml})$, were subjected to separation by RP-UHPLC-PDA and MS, the separation of all peaks was studied using different buffers and different with gradient elution by using 
different columns. Better separation was found in C18 column compared to other columns. The chromatographic separation was finally optimized and identified with UHPLC-PDA and MS on Zorbax SB-C18, $(100 \times 2.1) \mathrm{mm}, 1.8 \mu \mathrm{m}$ particle size columns with mobile phase containing water and acetonitrile with gradient composition. The flow rate of the mobile phase was $0.4 \mathrm{ml} / \mathrm{min}$ with column temperature of $40^{\circ} \mathrm{C}$ and detection wavelengths at $254 \mathrm{~nm}$ for impurity-1, impurity- 4 impurity-5, impurity-6, impurity-7, impurity-8, impurity-9 and 210 $\mathrm{nm}$ for impurity-2, impurity-3 and Injection volume $5 \mu$ l. The relative retention times of impurity-5, impurity-9, impurity-1, impurity-6, impurity-4, impurity-3, impurity-2, impurity-8 and impurity-7 were $0.31,0.40,0.43,0.57,0.80,1.18,1.24,1.62$ and 1.66 respectively.
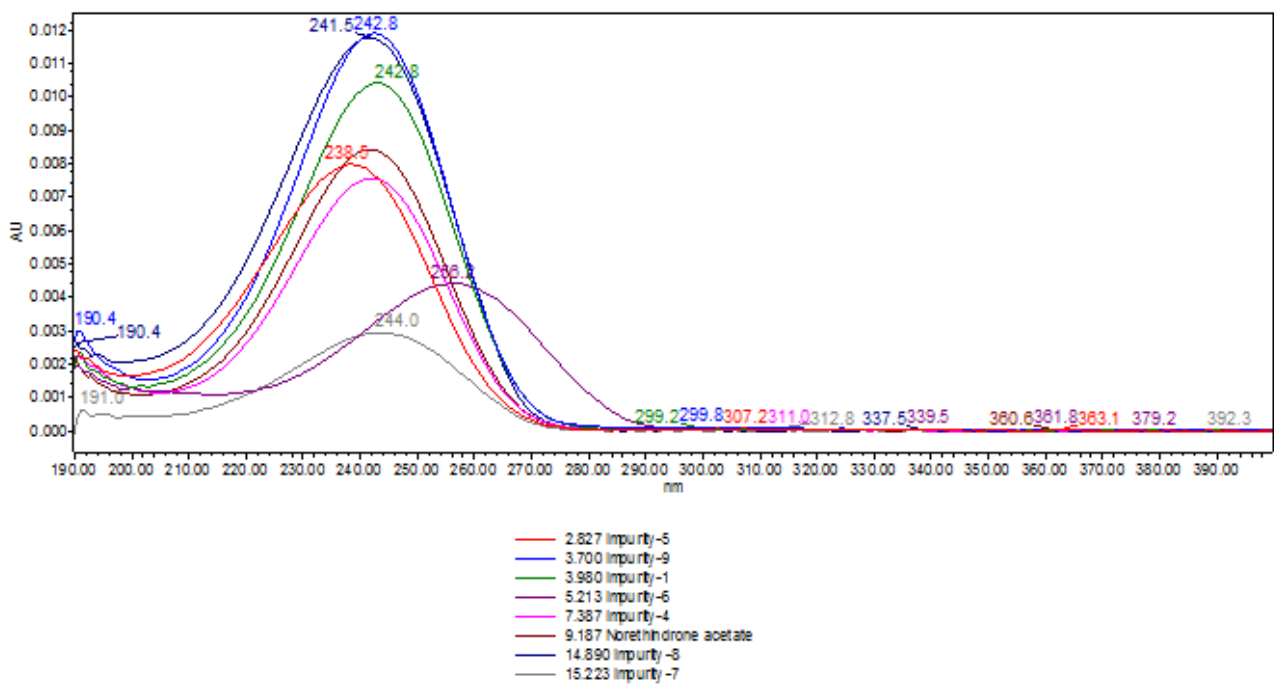

Fig. 2: Chromatogram for organic impurities standard solution at $254 \mathrm{~nm}$

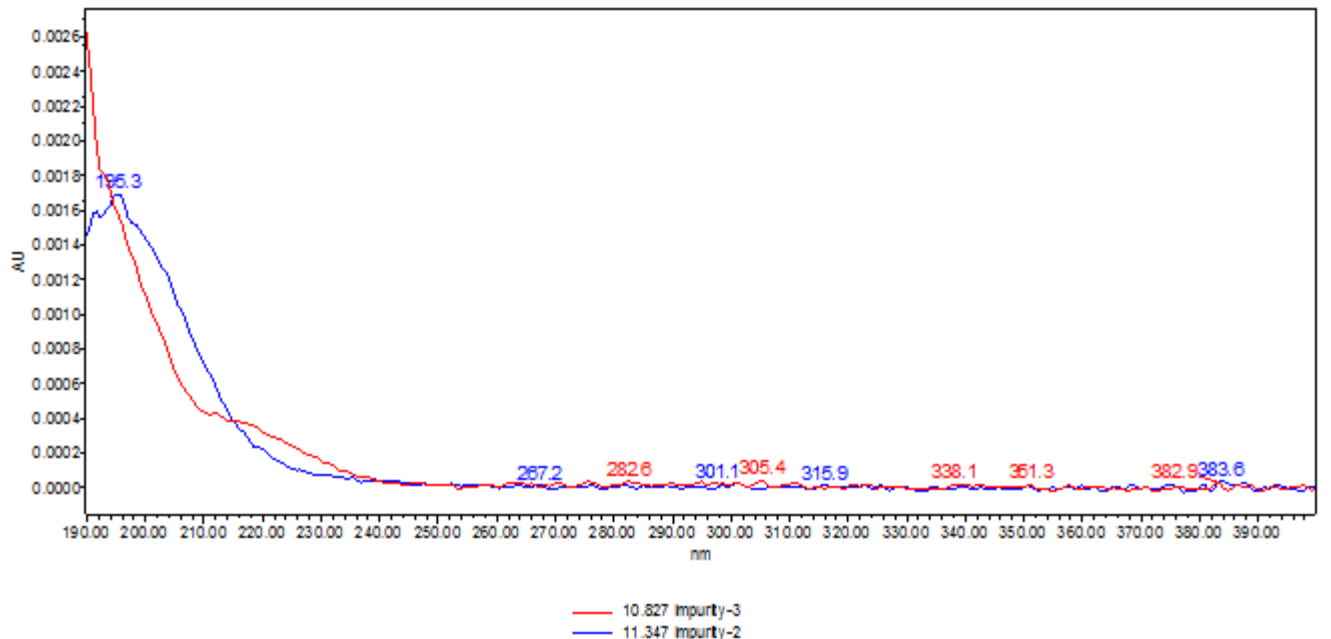

Fig. 3: Chromatogram for organic impurities standard solution at $210 \mathrm{~nm}$

\section{Specificity-stress study}

All forced degradation samples were analyzed with the mentioned chromatographic conditions using a PDA detector and MS to monitor the homogeneity and purity of the NA peak and its organic impurities. Individual impurities, tablet samples and NA sample were verified and proved to be non-interfering with each other thus proving the specificity of the method.

There is no interference at the RT (Retention Time) of NA and all organic impurities from the additional excipients. Degradation was not observed NA API and Tablets in peroxide, Thermal, photolytic and humidity stress studies.

Significant degradation was observed in acid and basic stress study conditions showed in fig. 4 to fig. 9. It is noteworthy that all the peaks due to degradation were well resolved from the peaks of NA and its impurities. For all Stress study samples, the purity angle found to be less than purity threshold and there was no purity flag (the purity flag is an indication of spectral homogeneity, compares the purity angle with the purity threshold by using empower software) for the NA and its impurities. Verification of peak purity indicates that there is no interference from degradation product, facilitating error-free quantification of NA impurities.

The degraded sample solutions of NA were assayed against the qualified standard for mass balance study. The mass balance of stressed samples was considered to be more than $99 \%$. Thus, the method is considered to be "Stability-indicating".

The specificity consequences and acid, base chromatogram along with peak purity and $\mathrm{m} / \mathrm{z}$ values were shown table 1 . Homogeneity of all degradation samples conformed by molecular mass. 


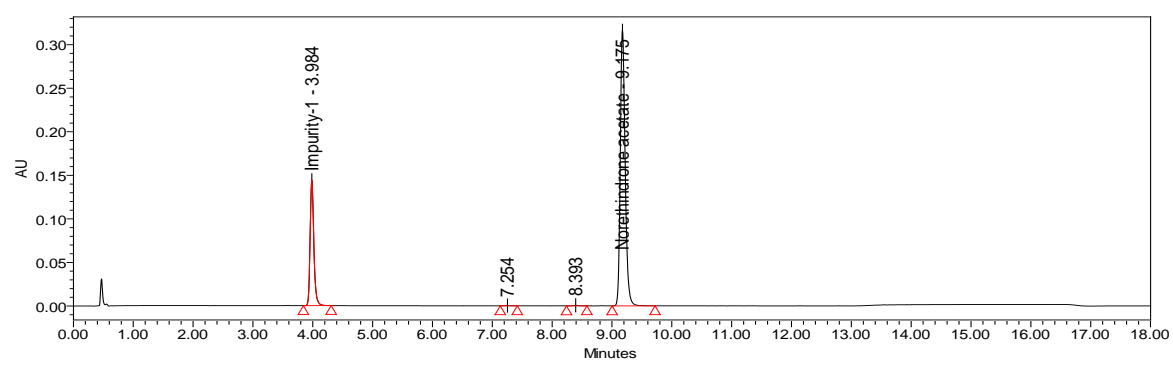

Fig. 4: Chromatogram of acid degradation solution



Fig. 5: MS spectra for acid degraded impurity

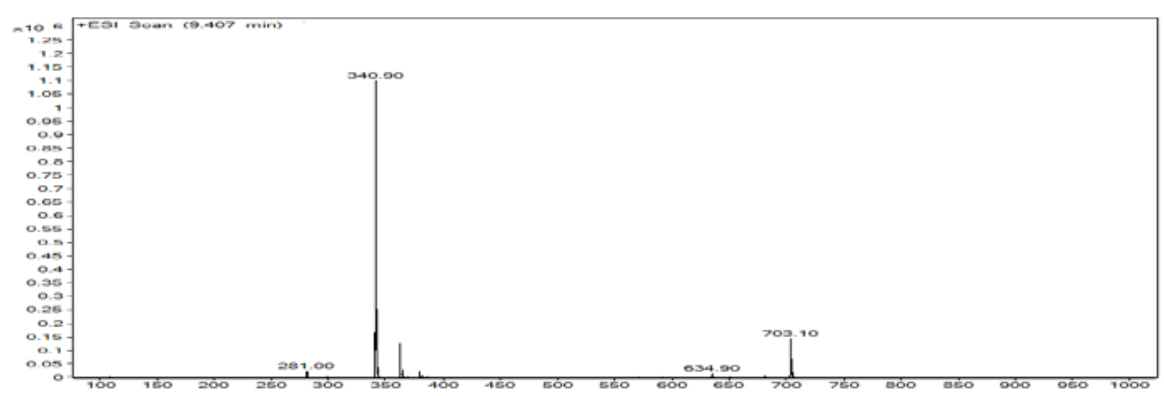

Fig. 6: MS spectra for NA

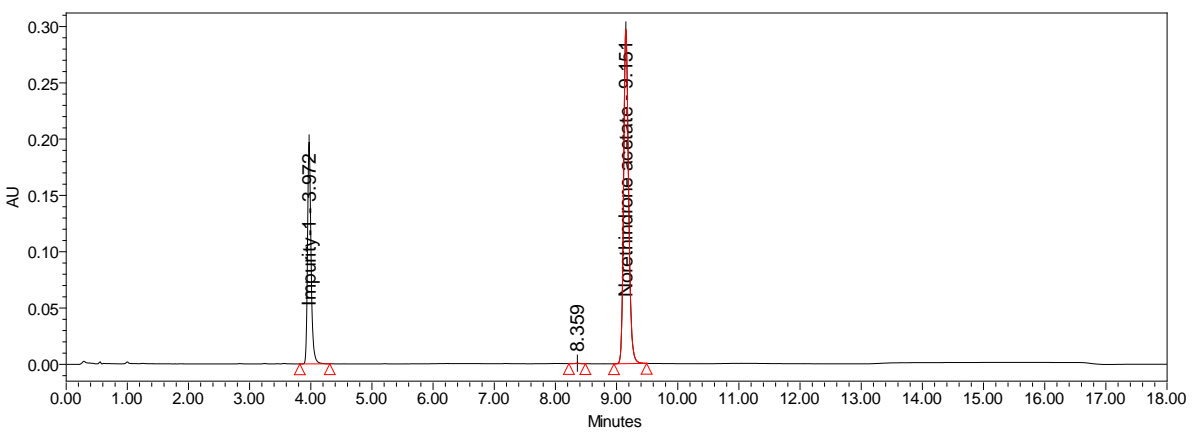

Fig. 7: Chromatogram of base degradation solution

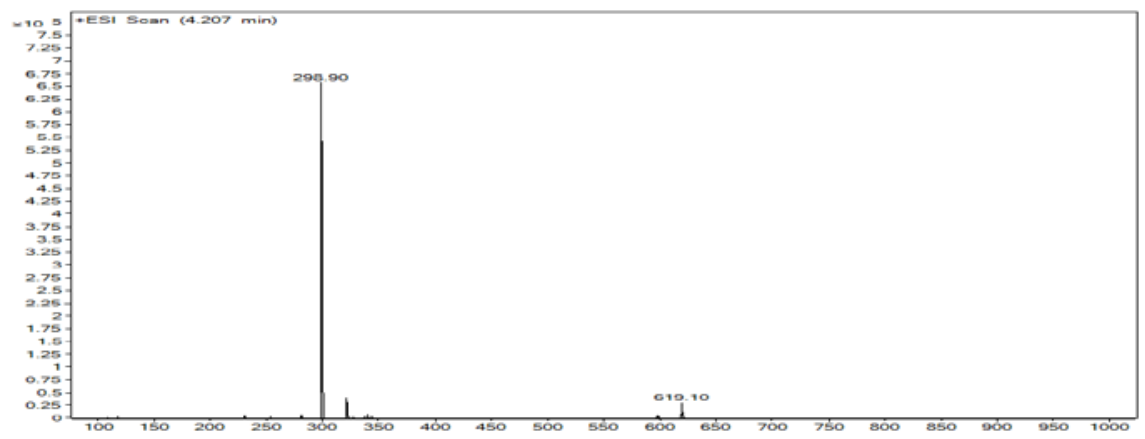

Fig. 8: MS spectra for base degraded impurity 


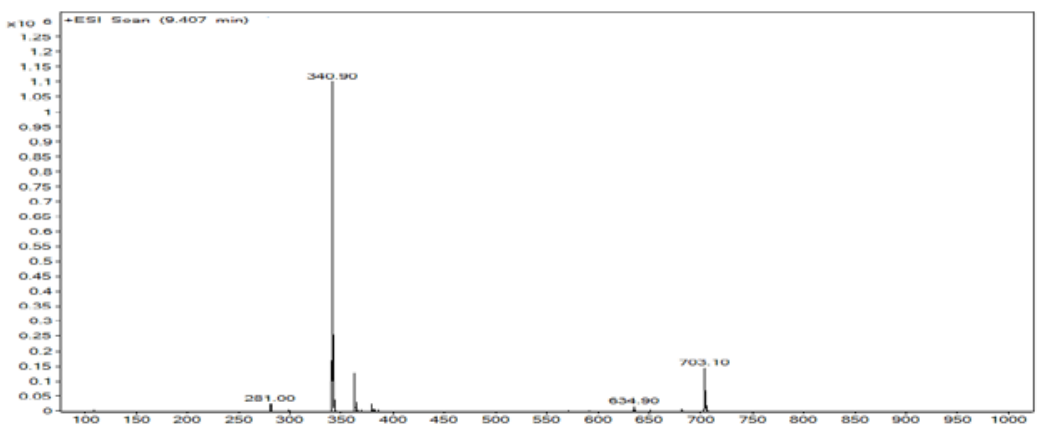

Fig. 9: MS spectra for NA

Table 1: Forced degradation data for NA

\begin{tabular}{|c|c|c|c|c|c|}
\hline \multirow[t]{2}{*}{ Degradation conditions } & \multicolumn{5}{|l|}{ NA } \\
\hline & $\%$ degraded & Purity angle & Purity threshold & $\begin{array}{l}\text { Mass balance } \\
(\%)\end{array}$ & $\begin{array}{l}\mathbf{m} / \mathbf{z} \\
\text { value }\end{array}$ \\
\hline $0.1 \mathrm{~N} \mathrm{HCl}$ bench to at $24 \mathrm{~h}$ at Room temperature & 25.8 (Impurity-1) & 0.013 & 0.242 & 99.3 & 340.9 \\
\hline $0.1 \mathrm{~N} \mathrm{NaOH}$ bench to at $1 \mathrm{~h}$ at Room temperature & 31.8 (Impurity-1) & 0.012 & 0.237 & 99.8 & 340.9 \\
\hline $\begin{array}{l}\text { Stressed with } 3 \% \mathrm{H} 2 \mathrm{O} 224 \mathrm{~h} \text { kept on bench top at Room } \\
\text { temperature }\end{array}$ & 0.47 & 0.014 & 0.251 & 99.6 & 341.0 \\
\hline Thermal at $105^{\circ} \mathrm{C}$ for $\mathrm{t} 48 \mathrm{~h}$ & 0.43 & 0.015 & 0.251 & 99.5 & 341.0 \\
\hline $\begin{array}{l}\text { Exposed to Visible light for about } 1.2 \text { Million Lux-hours } \\
\text { and UV light for about } 200 \text { Watt-hours/meter square }\end{array}$ & 0.49 & 0.013 & 0.250 & 100.2 & 341.0 \\
\hline Humidity $85 \mathrm{RH}$ and $85^{\circ} \mathrm{C}$ for $3 \mathrm{~d}$ & 0.40 & 0.018 & 0.247 & 100.2 & 341.0 \\
\hline
\end{tabular}

After development of the method it was subject to method validation as per ICH guidelines. The method was validated to demonstrate that it is suitable for its intended purpose by the prevailing procedure to evaluate adequate validation characteristics (System suitability, specificity, accuracy, precision, linearity, robustness, ruggedness, solution stability, LOD and LOQ. The typical chromatogram of organic impurity standard is shown in fig. 10, fig. 11 and results shown in table 2.

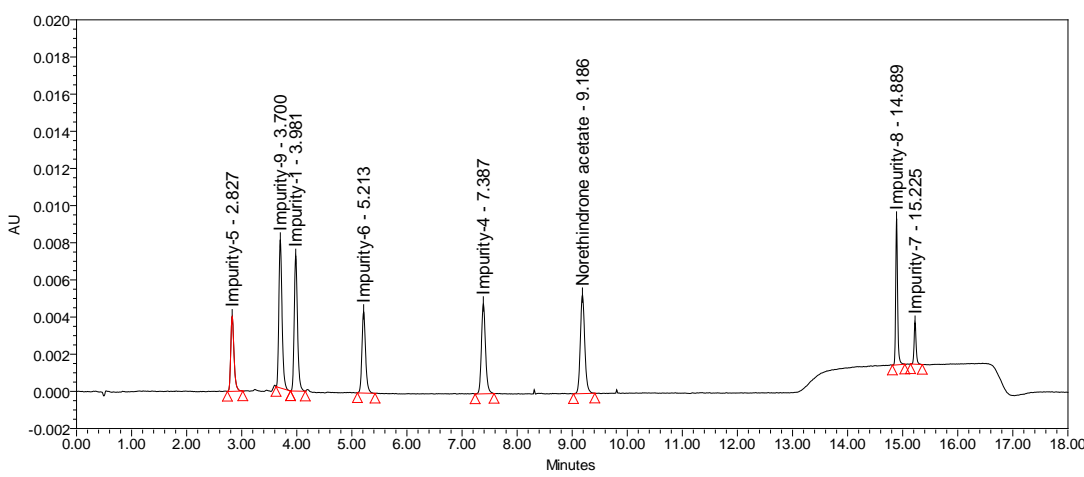

Fig. 10: Chromatogram for organic impurities standard preparation at $254 \mathbf{n m}$

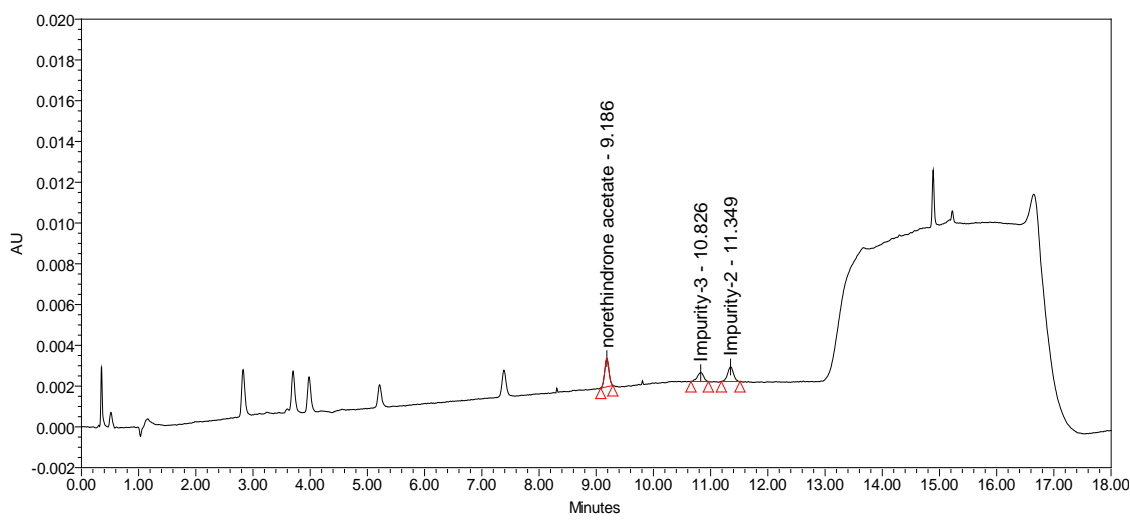

Fig. 11: Chromatogram for organic impurities standard preparation at $210 \mathrm{~nm}$ 
Table 2: System suitability

\begin{tabular}{|c|c|c|c|c|c|c|c|}
\hline \multicolumn{8}{|c|}{ [A]System suitability from Organic impurities solution at $254 \mathrm{~nm}$} \\
\hline \multirow[t]{2}{*}{ Compound name } & & \multirow[t]{2}{*}{ RT* } & \multirow[t]{2}{*}{ RRT\# } & \multirow[t]{2}{*}{ USP Resolution } & \multirow{2}{*}{$\begin{array}{l}\text { Mean } \\
(n=6)\end{array}$} & \multirow{2}{*}{$\begin{array}{l}\text { SD } \\
(n=6)\end{array}$} & \multirow{2}{*}{$\begin{array}{l}\% \text { RSD } \\
(n=6)\end{array}$} \\
\hline & & & & & & & \\
\hline Impurity-5 & & 2.83 & 0.31 & - & 16407 & 42.90 & 0.26 \\
\hline Impurity-9 & & 3.7 & 0.40 & 8.17 & 31985 & 96.54 & 0.30 \\
\hline Impurity-1 & & 3.98 & 0.43 & 2.59 & 30239 & 64.43 & 0.21 \\
\hline Impurity-6 & & 5.21 & 0.57 & 10.7 & 20074 & 68.70 & 0.34 \\
\hline Impurity-4 & & 7.39 & 0.80 & 16.88 & 25159 & 85.37 & 0.34 \\
\hline NA & & 9.19 & 1.00 & 12.64 & 29563 & 138.99 & 0.47 \\
\hline Impurity-8 & & 14.89 & 1.62 & 54.32 & 18839 & 81.91 & 0.43 \\
\hline Impurity-7 & & 15.22 & 1.66 & 5.16 & 5811 & 51.01 & 0.88 \\
\hline \multicolumn{8}{|l|}{$\mathrm{n}=$ Number of Injections } \\
\hline \multicolumn{8}{|c|}{ [B]System suitability from Organic impurities solution at $210 \mathrm{~nm}$} \\
\hline \multirow{2}{*}{\multicolumn{2}{|c|}{ Compound name }} & \multirow[t]{2}{*}{ RT* } & \multirow[t]{2}{*}{ RRT\# } & \multirow[t]{2}{*}{ USP Resolution } & Mean & SD & \% RSD \\
\hline & & & & & $(n=6)$ & $(n=6)$ & $(n=6)$ \\
\hline NA & & 9.19 & 1.00 & - & - & - & - \\
\hline Impurity-3 & & 10.83 & 1.14 & 9.88 & 3354 & 27.78 & 0.83 \\
\hline Impurity-2 & & 11.34 & 1.23 & 2.77 & 5132 & 36.48 & 0.71 \\
\hline \multicolumn{8}{|l|}{$\mathrm{n}=$ Number of Injection } \\
\hline \multicolumn{8}{|c|}{ [C] System suitability from assay solution } \\
\hline \multirow[t]{2}{*}{ Compound name } & RT* & \multirow{2}{*}{\multicolumn{2}{|c|}{ USP Tailing }} & \multirow[t]{2}{*}{ USP Plate count } & Mean & SD & \% RSD \\
\hline & & & & & $(n=5)$ & $(n=5)$ & $(n=5)$ \\
\hline NA & 9.2 & 1.29 & & 60678 & 2441582 & 2347.38 & 0.1 \\
\hline
\end{tabular}

$\mathrm{n}=$ Number of Injection, ${ }^{*}$ Retention Time and \# Relative Retention Time

\section{Precision and intermediate precision}

The RSD (\%) of NA peak during the study of assay precision was below $0.5 \%$. The RSD (\%) of the peak area for impurity-1, impurity2 , impurity-3, impurity-4, impurity-5, impurity-6, impurity-7, impurity-8 and impurity-9 in the study of organic impurity method precision was within $2.0 \%$.
These results confirm the precision of the analytical method is well. The RSD (\%) of the assay results obtained in the study of intermediate precision was within $0.5 \%$ and RSD (\%) for impurity-1, impurity-2, impurity-3, impurity-4, impurity-5, impurity-6, impurity-7, impurity- 8 and impurity- 9 were well within $2.0 \%$, confirming the ruggedness of the method and results shown in table 3.

Table 3: Precision data for NA assay and organic impurities

\begin{tabular}{|c|c|c|c|c|c|c|c|}
\hline \multirow[t]{2}{*}{ S. No } & \multirow[t]{2}{*}{ Name of the study } & \multirow{2}{*}{$\begin{array}{l}\text { Mean } \\
\text { (precision) }\end{array}$} & \multirow[t]{2}{*}{ SD } & \multirow[t]{2}{*}{ \% RSD } & Mean & SD & \% RSD \\
\hline & & & & & \multicolumn{3}{|l|}{ (Intermediate precision) } \\
\hline 1 & NA from Assay $(n=6)$ & 99.6 & 0.3 & 0.3 & 99.7 & 0.4 & 0.4 \\
\hline 2 & Imurity- 1 from OI $(n=6)$ & 98.9 & 0.7 & 0.7 & 99.1 & 0.6 & 0.6 \\
\hline 3 & Imurity-2 from OI $(n=6)$ & 98.1 & 0.5 & 0.5 & 98.7 & 0.7 & 0.7 \\
\hline 4 & Imurity-3 from OI $(n=6)$ & 99.6 & 0.6 & 0.6 & 99.3 & 0.6 & 0.6 \\
\hline 5 & Imurity-4from OI $(n=6)$ & 99.3 & 0.9 & 0.9 & 99.1 & 0.8 & 0.8 \\
\hline 6 & Imurity- 5 from OI $(n=6)$ & 98.3 & 0.8 & 0.8 & 98.7 & 0.7 & 0.7 \\
\hline 7 & Imurity- 6 from OI $(n=6)$ & 98.1 & 0.7 & 0.7 & 98.9 & 0.4 & 0.4 \\
\hline 8 & Imurity-7 from OI $(n=6)$ & 99.1 & 0.6 & 0.6 & 99.3 & 0.5 & 0.5 \\
\hline 9 & Imurity-8 from OI $(n=6)$ & 98.5 & 0.9 & 0.9 & 98.8 & 0.7 & 0.7 \\
\hline 10 & Imurity-9 from OI $(n=6)$ & 99.3 & 0.8 & 0.8 & 99.1 & 0.9 & 0.9 \\
\hline
\end{tabular}

$\mathrm{n}=$ Number of determinations

\section{LOD and LOQ}

The LOD for impurity-1, impurity-2, impurity-3, impurity-4, impurity-5, impurity-6, impurity-7, impurity- 8 and impurity- 9 were $0.001,0.01,0.015,0.002,0.002,0.002,0.001,0.002$ and $0.001 \%$ of the analyte concentration (i.e. $1000 \mu \mathrm{g} / \mathrm{ml}$ ), respectively, for a $5 \mu \mathrm{L}$ injection.

The LOQ for impurity-1, impurity-2, impurity-3, impurity-4, impurity-5, impurity-6, impurity-7, impurity-8 and impurity-9 were $0.003,0.03,0.05,0.006,0.006,0.006,0.003,0.006$ and $0.003 \%$ respectively, of the analyte concentration for $5 \mu \mathrm{L}$ injection. Precision (as \% RSD) at the LOQ concentration was below 5\% for all impurities.

\section{Linearity}

A linear calibration plot was generated for the assay method over the calibration range tested, i.e. $80-120 \mu \mathrm{g} / \mathrm{ml}$. The regression coef- ficient $\left(\mathrm{R}^{2}\right)$ was 0.9997 , the slope was 24761 , and the $Y$-intercept was 42094. A linear calibration plot was obtained for the OI method over the calibration range tested, i.e. from the 0.05 to $0.15 \%$ for impurity-1, impurity-2, impurity-3, impurity-4, impurity-5, impurity-6, impurity-7, impurity-8 and impurity-9. The regression coefficient was 0.99 for all impurities.

This result is indicative of excellent correlation between the peak area and concentrations of impurity-1, impurity-2, impurity-3, impurity-4, impurity-5, impurity-6, impurity-7, and impurity-8 and impurity-9.

\section{Accuracy}

$\%$ Recovery of NA ranged from 100.4 to $100.8 \%$ for drug samples and from 99.6 to $101.2 \%$ for pharmaceutical dosage forms. Recovery of Impurity-1, impurity-2, impurity-3, impurity-4, impurity-5, impurity-6, impurity-7, impurity- 8 and impurity- 9 from bulk drug samples ranged from 98.7 to $101.2 \%$ shown in table 4 and table 5 . 
Table 4: Accuracy data for NA assay

\begin{tabular}{|c|c|c|c|c|}
\hline \multicolumn{5}{|c|}{ Results of norethindrone assay accuracy study } \\
\hline S. No & Level (\%) $(n=3)$ & Mean (\% Recovery) & SD & \% RSD \\
\hline 1 & 80 & 100.6 & 0.2 & 0.2 \\
\hline 2 & 100 & 100.8 & 0.2 & 0.2 \\
\hline 3 & 120 & 100.4 & 0.2 & 0.2 \\
\hline \multicolumn{5}{|c|}{$\mathrm{n}=$ Number of determinations } \\
\hline \multicolumn{5}{|c|}{ Results of norethindrone tablets assay accuracy study } \\
\hline S. No & Level $(\%)(n=3)$ & Mean (\% Recovery) & SD & \% RSD \\
\hline 1 & 80 & 99.6 & 0.2 & 0.2 \\
\hline 2 & 100 & 100.2 & 0.3 & 0.3 \\
\hline 3 & 120 & 101.2 & 0.3 & 0.3 \\
\hline \multicolumn{5}{|c|}{$\mathrm{n}=$ Number of determinations } \\
\hline
\end{tabular}

Table 5: Accuracy data for NA organic impurities

\begin{tabular}{|c|c|c|c|c|}
\hline \multicolumn{5}{|c|}{ Results of Impurity-1 Accuracy Study } \\
\hline S. No & Level (\%) $(n=3)$ & Mean (\% Recovery) & SD & \% RSD \\
\hline 1 & 0.05 & 99.8 & 0.6 & 0.6 \\
\hline 2 & 0.1 & 100.6 & 0.5 & 0.5 \\
\hline 3 & 0.15 & 99.9 & 0.2 & 0.2 \\
\hline \multicolumn{5}{|c|}{ Results of Impurity-2 Accuracy Study } \\
\hline S. No & Level $(\%)(n=3)$ & Mean (\% Recovery) & SD & \% RSD \\
\hline 1 & 0.05 & 98.9 & 0.4 & 0.4 \\
\hline 2 & 0.1 & 99.4 & 0.8 & 0.8 \\
\hline 3 & 0.15 & 99.3 & 0.6 & 0.6 \\
\hline \multicolumn{5}{|c|}{ Results of Impurity-3 Accuracy Study } \\
\hline S. No & Level (\%) $(n=3)$ & Mean (\% Recovery) & SD & \% RSD \\
\hline 1 & 0.05 & 100.2 & 0.5 & 0.5 \\
\hline 2 & 0.1 & 99.5 & 0.3 & 0.3 \\
\hline 3 & 0.15 & 100.8 & 0.7 & 0.7 \\
\hline \multicolumn{5}{|c|}{ Results of Impurity-4 Accuracy Study } \\
\hline S. No & Level $(\%)(n=3)$ & Mean (\% Recovery) & SD & \% RSD \\
\hline 1 & 0.05 & 99.3 & 0.6 & 0.6 \\
\hline 2 & 0.1 & 98.7 & 0.4 & 0.4 \\
\hline 3 & 0.15 & 100.4 & 0.2 & 0.2 \\
\hline \multicolumn{5}{|c|}{ Results of Impurity-5 Accuracy Study } \\
\hline S. No & Level $(\%)(n=3)$ & Mean (\% Recovery) & SD & \% RSD \\
\hline 1 & 0.05 & 98.8 & 0.2 & 0.2 \\
\hline 2 & 0.1 & 99.4 & 0.7 & 0.7 \\
\hline 3 & 0.15 & 99.3 & 0.4 & 0.4 \\
\hline \multicolumn{5}{|c|}{ Results of Impurity-6 Accuracy Study } \\
\hline S. No & Level (\%) $(n=3)$ & Mean (\% Recovery) & SD & \% RSD \\
\hline 1 & 0.05 & 100.1 & 0.4 & 0.4 \\
\hline 2 & 0.1 & 100.6 & 0.3 & 0.3 \\
\hline 3 & 0.15 & 99.8 & 0.8 & 0.8 \\
\hline \multicolumn{5}{|c|}{ Results of Impurity-7 Accuracy Study } \\
\hline S. No & Level $(\%)(n=3)$ & Mean (\% Recovery) & SD & \% RSD \\
\hline 1 & 0.05 & 101.2 & 0.3 & 0.3 \\
\hline 2 & 0.1 & 99.8 & 0.7 & 0.7 \\
\hline 3 & 0.15 & 100.7 & 0.6 & 0.6 \\
\hline \multicolumn{5}{|c|}{ Results of Impurity-8 Accuracy Study } \\
\hline S. No & Level $(\%)(n=3)$ & Mean (\% Recovery) & SD & \% RSD \\
\hline 1 & 0.05 & 99.5 & 0.4 & 0.4 \\
\hline 2 & 0.1 & 100.7 & 0.7 & 0.7 \\
\hline 3 & 0.15 & 100.3 & 0.9 & 0.9 \\
\hline \multicolumn{5}{|c|}{ Results of Impurity-9 Accuracy Study } \\
\hline S. No & Level $(\%)(n=3)$ & Mean (\% Recovery) & SD & \% RSD \\
\hline 1 & 0.05 & 100.4 & 0.3 & 0.3 \\
\hline 2 & 0.1 & 99.5 & 0.5 & 0.5 \\
\hline 3 & 0.15 & 100.2 & 0.3 & 0.3 \\
\hline \multicolumn{5}{|c|}{$\mathrm{n}=$ Number of determinations } \\
\hline
\end{tabular}

\section{Robustness}

No significant effect was observed on system suitability parameters such as \%RSD, tailing factor, or the theoretical plates and resolution of NA when small but deliberate changes were made in chromatographic conditions. Thus, the method was considered to be robust with respect to variability in applied conditions.

\section{Solution stability}

No significant changes were found in the content of NA method during solution stability and mobile phase stability experiments when performed. Solution stability and mobile phase stability experimental data confirm that the sample solution and mobile phases used during the assay and impurity determination were stable for at least $48 \mathrm{~h}$ at room temperature. 


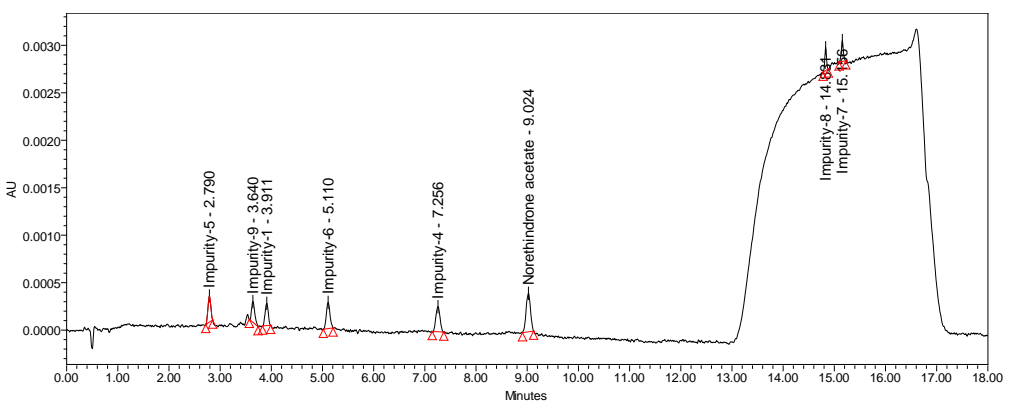

Fig. 12: Chromatogram for LOQ solution at $254 \mathrm{~nm}$

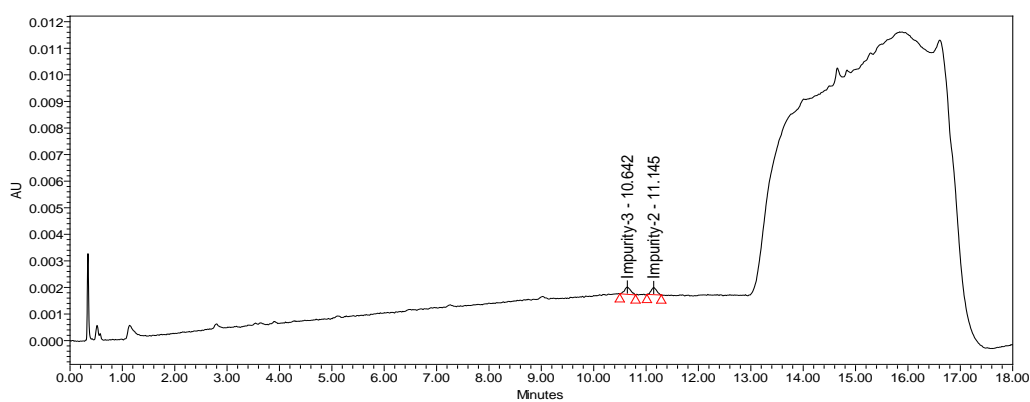

Fig. 13: Chromatogram for LOQ solution at $210 \mathrm{~nm}$

\section{DISCUSSION}

Proposed assay and impurities procedure of NA-API and Tablets, demonstrate that the system suitability parameter may fall within $\pm 2 \%$ range during validation studies of the method. This procedure was rapid and sensitive compare to other reference procedures [1, 2, 3-5]. Performed the specificity, linearity, accuracy, precision, LOD and LOQ and robustness of the method to cover the validation range from $0.05 \%$ to $0.15 \%$ of impurities and $80 \%$ to $120 \%$ of the assay. The obtained LOD values are $0.001 \%$ to $0.015 \%$ and LOQ values are $0.003 \%$ to $0.05 \%$ of impurities.

These predicted LOQ values are well below the disregard limit of EP NA monograph [1]. The mean recovery of the API and its impurities was in the range of $98.0-102 \%$ for each level was replicated for three times. Recovery data state that the proposed method is accurate and reproducible. The observed linearity correlation was $>0.99$. This indicates that the method was linear. The lower value of the \% RSD of the assay and its impurities indicates that the method is precise. These results concluded that the proposed method is speedy, sensitive and specific method for the analysis of NA API and PF.

Related substances HPLC-method in EP NA monograph [1] trial was conducted based on EP procedure. In this method longer runtime and also Impurity 2 and Impurity 3 were not separated completely, the proposed method was more specific for all impurities including Impurity 2 and Impurity 3. References [2, 3-5] were not suitable for impurities separation and quantification of NA in tablets. This developed method can be suitable for API and PF for assay and impurities methods. Hence this procedure is more specific, sensitive and rapid procedure for NA API and PFs.

\section{CONCLUSION}

NA assay and organic impurities in both API drug and pharmaceutical dosage form with orthogonal detectors were used to confirm the identity of compounds in UHPLC-PDA and MS. The UHPLC-PDA provides UV spectral information to distinguish isobaric compounds and the Mass detector provides mass spectra to distinguish with identical UV spectra. The UHPLC-PDA and MS method is validated as per ICH guidelines and found to be specific, precise, linear, accurate, rugged, and robust. The developed method can be used for stability analysis of both NA API and PF.

\section{ACKNOWLEDGEMENT}

The authors wish to thank the management of the United States pharmacopeia-India (P) Ltd for facilities and cooperation.

\section{AUTHORS CONTRIBUTION}

J. Satish as the first author had done almost all the work of this publication. K. Surendra Babu helped as a second analyst to execute the studies. P. Radha Krishnan and was guided for the conceptualization of the study and writing the publication.

\section{CONFLICT OF INTERESTS}

All the authors declare that they do not have any conflict of interest.

\section{REFERENCES}

1. European Pharmacopoeia; 2017.

2. Hisham Hashem, Soad Abd El-hay, Thomas Jira. A rapid stability indicating HPLC-method for determination of norethisterone acetate in plasma, tablets and in a mixture with other steroids. Int J Pharm Pharm Sci 2015;7:279-82.

3. Khattab FI, Ashour FM, Amer MM. Argentometric methods for the determination of acetylenic steroids, ethinyloestradiol and norethisterone. J Pharm Belgique 1983;38:147-55.

4. Boglarka B, Geza R, Maria M, Zoltan V, Katalin FF. OPLC, a method between TLC and HPLC, for purity testing of norethisterone bulk drug substance and tablet. Planar Chromatogr 2003;16:359-62.

5. Rizk MS, Zakhari NA, Walash MI, Toubar SS, Brooks CJ, Anderson R. Gas chromatography and mass spectrometry of dimethylethylsilyl ether derivatives of norethisterone metabolites in plasma. Acta Pharm Nord 1991;3:205-10.

6. JT Carstensen, CT Rhodes. Eds. Drug Stability Principles and Practices; 2000.

7. ICH Guidelines on Validation of Analytical procedures, Text and Methodology, Q2(R1); 1994.

8. United States Pharmacopeia, United States Pharmacopeial Convention, Rockville; 2016. 